\title{
Many routes lead to Rome: potential causes for the multi-route migration system of Red Knots, Calidris canutus islandica
}

\author{
Silke Bauer, ${ }^{1,2,4,5}$ Bruno J. Ens, ${ }^{1,3}$ and Marcel KlaAssen ${ }^{1,4}$ \\ ${ }^{1}$ Netherlands Institute of Ecology (NIOO-KNAW), P.O. Box 1299, NL-3600 BG Maarssen, The Netherlands \\ ${ }^{2}$ Swiss Ornithological Institute, CH-6204 Sempach, Switzerland \\ ${ }^{3}$ SOVON Dutch Centre for Field Ornithology, SOVON-Texel, P.O. Box 59, NL-1790 AB Den Burg (Texel), The Netherlands \\ ${ }^{4}$ Centre for Integrative Ecology, Deakin University, Waurn Ponds VIC 3297 Australia
}

\begin{abstract}
Migrants, such as birds or representatives of other taxa, usually make use of several stopover sites to cover the distance between their site of origin and destination. Potentially, multiple routes exist, but often little is known about the causes and consequences of alternative migration routes. Apart from their geographical distribution, the suitability of potential sites might play an important role in the animals' decisions for a particular itinerary.

We used an optimal-migration model to test three nonmutually exclusive hypotheses leading to variations in the spring migration routes of a subspecies of Red Knot, Calidris canutus islandica, which migrates from wintering grounds in Western Europe to breeding grounds in Greenland and the Canadian Arctic: the breeding location hypothesis, the energy budget hypothesis, and the predation risk hypothesis. Varying only breeding location, the model predicted that birds breeding in the Canadian Arctic and on West Greenland stop over on Iceland, whereas birds breeding in East and Northeast Greenland migrate via northern Norway, a prediction that is supported by empirical findings. Energy budgets on stopover sites had a strong influence on the choice of route and staging times. Varying foraging-intensity and mass-dependent predation risk prompted the birds to use less risky sites, if possible. The effect of simultaneous changes in the energy budget and predation risk strongly depended on the site where these occurred.

Our findings provide potential explanations for the observations that $C$. canutus islandica uses a diverse array of migration routes. Scrutinizing the three alternative driving forces for the choice of migratory routes awaits further, specific data collection in rapidly developing fields of research (e.g., predation risk assessment, GPS tracking). Generally, the type of modeling presented here may not only highlight alternative explanations, but also direct follow-up empirical research.
\end{abstract}

Key words: Calidris canutus islandica; food intake rate; Icelandic Red Knot; migratory connectivity; optimal migration; predation risk; shorebirds; stochastic dynamic programming model.

\section{INTRODUCTION}

Animals migrating between distant sites typically need a number of stopovers to replenish body stores in preparation for the next migratory leg. Depending on the existence and distribution of suitable habitat patches that may serve as stopover sites, multiple routes are often possible. Alternative migration routes potentially differ in many factors, including: (1) the cost to travel between suitable sites, which are dependent on distance and weather conditions, (2) fuel-depositing conditions (and thus, risk of starvation), which is dependent on local food availability or competition with conspecifics, (3) predation risk, which is dependent on local abundance of predators, and (4) energy expenditure, dependent on local climatic conditions.

Manuscript received 17 July 2009; accepted 24 August 2009. Corresponding Editor: M. Wikelski.

${ }^{5}$ E-mail: s.bauer@nioo.knaw.nl
Theoretically, the eventual reward of taking a particular migration route is determined by survival en route, and the expected reproductive success on arrival at the breeding grounds. Survival en route is probably mainly determined by the presence of predators on stopover sites (Lank et al. 2003), and by adverse weather conditions during demanding periods of exercise (e.g., Newton 2007). Similarly, in seasonal environments, arrival time and condition on the breeding grounds are likely correlates of reproductive success and survival (Drent et al. 2003, Morrison et al. 2007). Arriving late may come at the cost, for example, of the best territories being already occupied, or not being able to finish the reproductive bout successfully, but arriving too early may risk experiencing adverse weather conditions, and the possibility of starvation (Boyd and Piersma 2001). Similarly, individuals arriving in good condition are probably better able to survive adverse conditions and to invest more in offspring (Drent et al. 2003, Morrison et al. 2007). 
Thus, the conditions individuals encounter during migration, including stopover periods, have important implications for their fitness, and thus ultimately, for the fate of the whole population. Once it is known how conditions on stopover sites influence an animal's fitness, we can also predict the consequences of habitat changes on one or more stopover sites (e.g., Weber et al. 1999, Klaassen et al. 2006). Such knowledge is all the more pressing in the face of the many threats to migrating animals: habitat destruction, creation of obstacles and barriers, overexploitation, and climate change (Piersma 2007, Wilcove and Wikelski 2008). According to these authors, the greatest scientific challenge lies in understanding "the demographic connectivity of migration - how events at any one stage of the migratory cycle affect other stages and the overall population trajectory," and "the decision rules by which migratory animals determine where to go, how long to stay, and when to leave." An important contribution to this goal is the understanding of variation in migration routes and the identification of (local) environmental factors that influence the choice of routes. Variation in migration routes is a phenomenon appearing in many migratory species across many taxa: insects (e.g., Brower 1995), fish (e.g., Jørgensen et al. 2008), reptiles (e.g., Hays et al. 2006), birds (Newton 2007), and mammals (e.g., Best et al. 1998).

Despite the fact that this is a general phenomenon, little is known about the factors underlying and driving the use of different routes. We need to identify these factors if we are to understand migration. Factors acknowledged for their role in shaping migration routes are barriers, historical and genetic factors, energy costs of transport, and orientation and navigation abilities (Alerstam et al. 2003). In addition to such rather "ultimate" causes, many proximate factors may play an important role, but have so far been little scrutinized. This may be (partly) because answering such relevant questions quickly becomes a highly complex exercise. Therefore, we employed an optimal-migration modeling approach (Weber et al. 1998) to reveal the relative importance of environmental, site-specific parameters in determining migratory behavior, and in particular, to identify potential reasons for the existence of multiple migration routes. To this end, we applied such a model to the spring migration of a subspecies of the Red Knot, Calidris canutus islandica (for simplicity, hereafter referred to as Icelandic Knots). Like many shorebirds, the population of Icelandic Knots has suffered considerable declines over the last decades, and is therefore regarded as a threatened species (BirdLife International 2004).

Icelandic Knots winter at various key sites in Western Europe, and their breeding grounds stretch from East Greenland to the Canadian Arctic (Fig. 1). Birds leave the wintering areas by the end of March or early April, heading for the first stopover sites in the United Kingdom or Germany (Fig. 2). Here, they stay

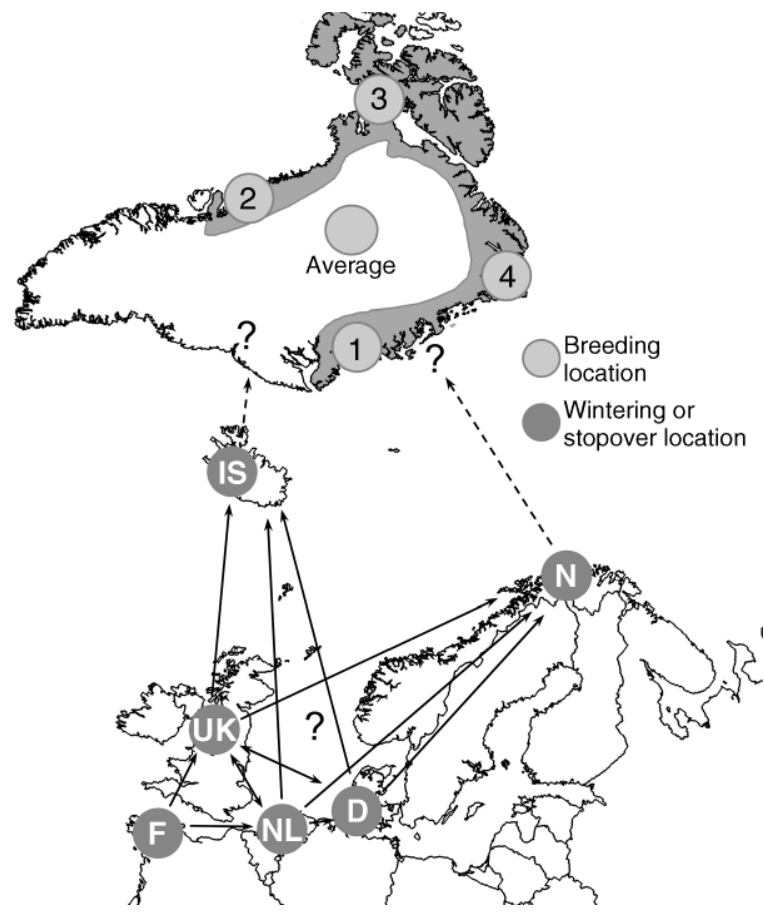

FIG. 1. Key sites used by Icelandic Knots (Calidris canutus islandica) during spring migration: tidal areas in Brittany, France (F), Dutch Wadden Sea (NL), and Morecambe Bay (UK) are used over winter. In early spring, birds move to the German Wadden Sea (D) or the United Kingdom and later in the season, farther north to Norway (N) or Iceland (IS). The Arctic breeding grounds of Icelandic Knots stretch from East Greenland to northern Canada (as indicated by the shaded areas, after Davidson et al. [1986]). In the model, we used an average breeding location, and additionally, four exemplary locations at the fringes of the breeding range (locations 1-4).

approximately 4-6 weeks until early May before migrating to stopover sites in Iceland or Norway. After staying there another 3-4 weeks (end of May), the next migratory leg leads them to their Arctic breeding grounds. Although it has been stated that part of the population migrates to the breeding grounds via Iceland and another part via Norway, it remained obscure what the causes (and consequences) for different routes were, whether these differences in the last stopover site involved choosing different sites earlier during migration or wintering as well, and which role site conditions played in the choice of migration routes. Therefore, we formulated the following three hypotheses and tested their potential to lead to different migration routes and/or staging durations in Icelandic Knots during spring migration.

Breeding and wintering location hypothesis.-Icelandic Knots breed in a widespread area from the east coast of Greenland to the Canadian Arctic (from $70^{\circ} \mathrm{N}, 24^{\circ} \mathrm{W}$ to $70^{\circ} \mathrm{N}, 55^{\circ} \mathrm{W}$, and from $80^{\circ} \mathrm{N}, 13^{\circ} \mathrm{W}$ to $82^{\circ} \mathrm{N}, 63^{\circ} \mathrm{W}$; Fig. 1). They also winter in different regions: in several large estuaries in the United Kingdom, in the Dutch Wadden Sea (NL), and in coastal areas of Brittany, in 


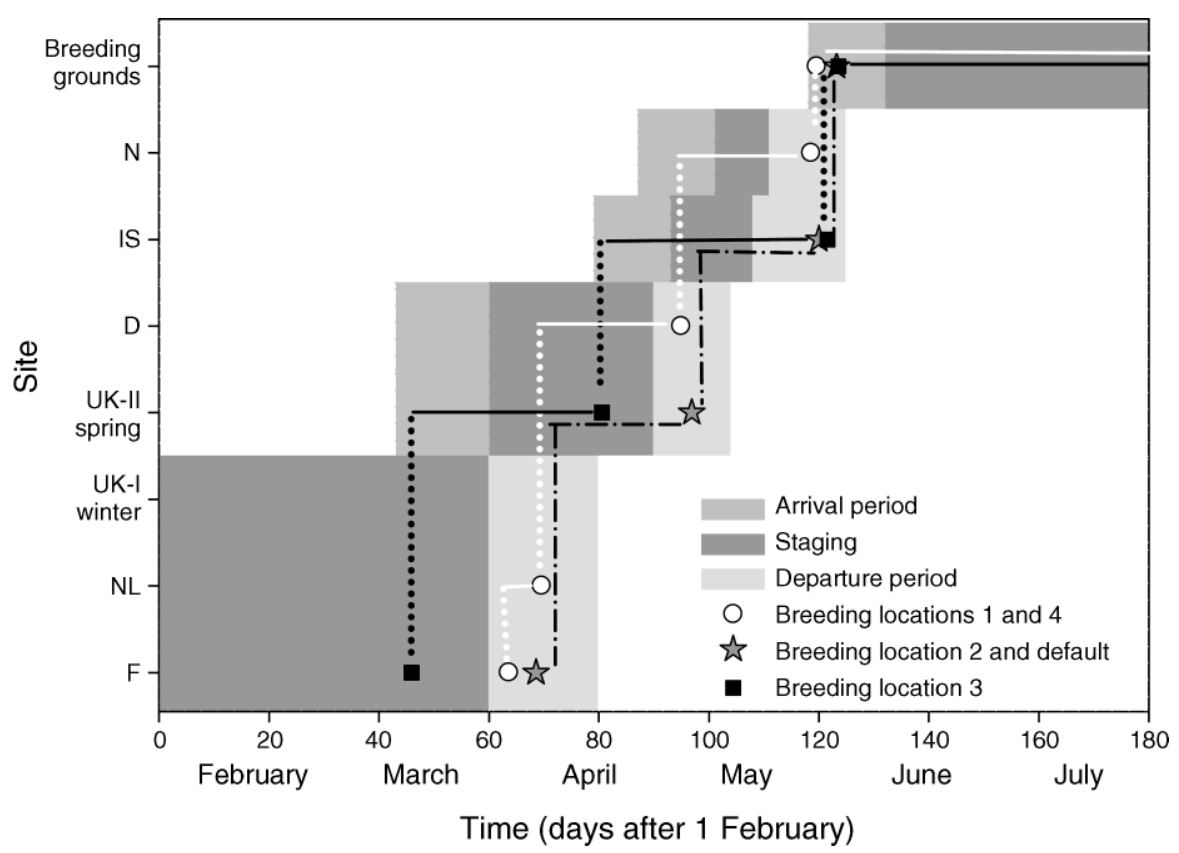

FIG. 2. Empirically observed arrival, departure, and staging times (light and dark gray areas, respectively) of C. canutus islandica on the wintering sites in France (F), The Netherlands (NL), and the United Kingdom (indicated as UK-I winter); in the early-spring staging sites in Germany (D) and the United Kingdom (indicated as UK-II spring); and in the late-spring staging sites in Iceland (IS) and Norway (N). Data were derived from Davidson and Wilson (1992), Piersma et al. (2005), Wilson and Strann (2005), and Wilson et al. (2006). Furthermore, departure and staging times from the breeding location scenario predicted by the model (only shown for wintering location in France) are depicted: breeding locations 1 and 4 (open circles, white lines); breeding locations 2 and average breeding location (gray stars, dashed lines); breeding location 3 (solid squares, dotted lines).

France $(\mathrm{F})$. Both their wintering site and their exact breeding location might influence the choice of migration route, through differences in distances between the various sites and accompanying flight costs.

The quality of a site might be described by food availability and predation risk; the first determines a site's potential for refueling, and the latter its safety, i.e., the probability of survival when staging there.

Energy budget hypothesis.-The quantity and quality of available food may be an important determinant of staging decisions, since the preparation for the next migration step strongly depends on the speed with which birds can replenish their body stores. Thus, intake rates on sites might play an important role in stopover site choice. However, besides food availability, daily energy expenditure (DEE) is also an important determinant of the time needed to replenish body stores, and is typically influenced by local weather, and particularly temperature conditions.

Predation risk hypothesis.-Differences in predation risk may lead to preferences among stopover sites. Predation risk may vary depending on the type of predator, the (mass-related) motility of its prey, and the activity in which its potential prey engages. We therefore, distinguish between mass- or fuel-load-dependent predation risk, activity- or foraging-intensity-dependent predation risk, and background predation risk, which is indifferent to the migrant's behavior and condition.

\section{Model and Methods}

\section{Model description and parameterization}

The general setup of the optimal-migration model has been described earlier (Weber et al. 1998), and we therefore refrain from giving a full model description here. Instead, we briefly explain the model's fundamental characteristics and provide a full description in Appendix A; we also describe parameter estimations in detail in Appendix B.

The model covered the spring migration to the breeding grounds. Birds were characterized by their body stores and location, i.e., site, at a particular day. We considered the potential wintering and stopover sites of Icelandic Knots (Fig. 1), and all sites were characterized by food availability, energy expenditure, and predation risk (see Model scenarios). Within each timestep, i.e., one day, a bird decided either to remain and forage on its present site, or to continue migration to another site. Decisions depended on the bird's current state, i.e., body stores, time of the year and expected conditions on the present and subsequent sites.

Once the bird had reached the breeding grounds, we no longer modeled its decisions, but assumed that its current reproductive success was determined by body stores at arrival and arrival time.

With the dynamic programming equations (Appendix A), the optimal migratory behavior was calculated for 
all combinations of body stores, dates, and sites (Houston and McNamara 1999). Subsequently, we used this optimal behavior in simulations of individual trajectories, which generated predictions on the migration route taken and the staging times on the stopover sites.

In the model, body store accumulation, energy expenditure, and intake rate were all converted to a single unit and expressed in body stores per day (grams of fuel per day, which represented $32.77 \mathrm{~kJ} / \mathrm{g}$ based on Wiersma and Piersma [1994]). We characterized food availability on the wintering and part of the staging sites, i.e., F, NL, UK, and D, with an estimate of the maximum intake rates of $13 \mathrm{~g}$ fuel/d (see Appendix A and Appendix B: Fig. B1 for details). The last stopover sites before the breeding grounds, i.e., Iceland and Norway, have higher intake rates $(14 \mathrm{~g}$ fuel/d) than the sites for the earlier legs of migration, a phenomenon found for all knot subpopulations worldwide (Piersma et al. 2005).

We estimated daily energy expenditure (DEE) and its temporal dynamics from monthly mean temperatures on the sites (Wiersma and Piersma 1994, Piersma et al. 2005). DEE generally decreased in the course of the season and was higher in the northerly sites (in Iceland and Norway $\sim 2 \mathrm{~g} / \mathrm{d}$ higher compared to the other sites).

Net fueling rates resulted from the difference between gross intake rate and energy expenditure, and reached, dependent on site and time, maximum values of $1-5 \mathrm{~g}$ fuel $/$ d.

Predation risk is generally influenced by the abundance of predators (background predation risk), but also by the bird's state and behavior, i.e., its body mass and foraging behavior. All three facets were used in assessing total predation risk (see Appendix A: Eq. A.4). Unfortunately, empirical values for predation risk are virtually nonexistent to date, and therefore we estimated the coefficients for background predation risk, foragingintensity-dependent and mass-dependent predation risk, such that they did not exceed empirically estimated survival during spring migration (see Appendix A).

\section{Model scenarios and analyses}

Key sites for wintering Icelandic Knots can be found in Brittany, The Netherlands, and the United Kingdom. We used these three locations as wintering sites in the model. As a breeding site, we used an average location in the center of the breeding area in most scenarios, unless otherwise stated.

In the breeding locations scenario, we used four additional breeding locations at the fringes of the breeding range, embracing this vast area (Fig. 1). This changed the distances between potential staging and breeding sites, and thus the energetic costs of migratory flights.

In the energy budget scenario, we systematically changed maximum gross intake rates on all sites independently. For each model run, we set maximal intake rates on all sites at their standard value, except for the intake rate on the focal site, which was varied relative to its standard value by $-20 \%,-5 \%,+5 \%,+20 \%$, $+50 \%$, and $+100 \%$. This procedure was repeated for all sites. A similar procedure was employed to assess the effect of variations in daily energy expenditures on the sites (Appendix B: Fig. B1).

In the predation risk scenario, we varied the background predation risk $b_{0}$, the coefficients for foragingintensity-dependent predation risk, $b_{1}$, and fuel-loaddependent predation risk, $b_{2}$, independently and systematically on all sites by multiplying their standard values of $b_{0}=10^{-5}, b_{1}=10^{-3}, b_{2}=10^{-2}$ with the factors: 0.1 , $0.5,0.8,1.2,2.0$, and 10.0 . Thus the coefficients varied over three orders of magnitude from 0.1 to 10 times their standard values.

For all scenarios we calculated the concomitant route taken and the staging times on all sites along that route, as well as the overall survival.

\section{RESUlts \\ Breeding location}

There was considerable variation in choice of migration routes for the different breeding destinations. Birds heading for breeding sites along the East Coast of Greenland (breeding locations 1 and 4) were predicted to fly via the German Wadden Sea and Norway (Fig. 3). Birds breeding in the Nearctic (locations 2 and 3) were predicted to use staging areas in the United Kingdom and Iceland. The route predictions were independent of the wintering location, whether it was France, The Netherlands, or the United Kingdom (Fig. 3).

Generally, the predicted timing of the various journeys corresponded well with the empirically observed staging and departure times (Fig. 2). Still, considerable differences in timing existed between birds aiming for different breeding destinations. Birds heading for location 3 departed earliest from their wintering grounds. These left $\sim 30$ days earlier than the latest birds, which were heading for location 2 and the average location. Although these differences in timing of departure continued to exist along most of the migration route, departures from the last stopover sites before the breeding grounds were highly synchronized, indicating the great importance of arriving in time. Survival was high $(>80 \%)$ throughout all combinations of breeding and wintering sites.

\section{Food availability}

Variations in maximum intake rates substantially influenced the migration route. A common pattern was that sites with even slightly higher intake rates $(+5 \%)$ than in the standard parameter setting were strongly favored, and vice versa, sites with lower than standard intake rates were avoided. However, both the site where the intake rate was changed, and the direction of change, determined whether this only resulted in adjusted staging times, or also altered the route taken. When 


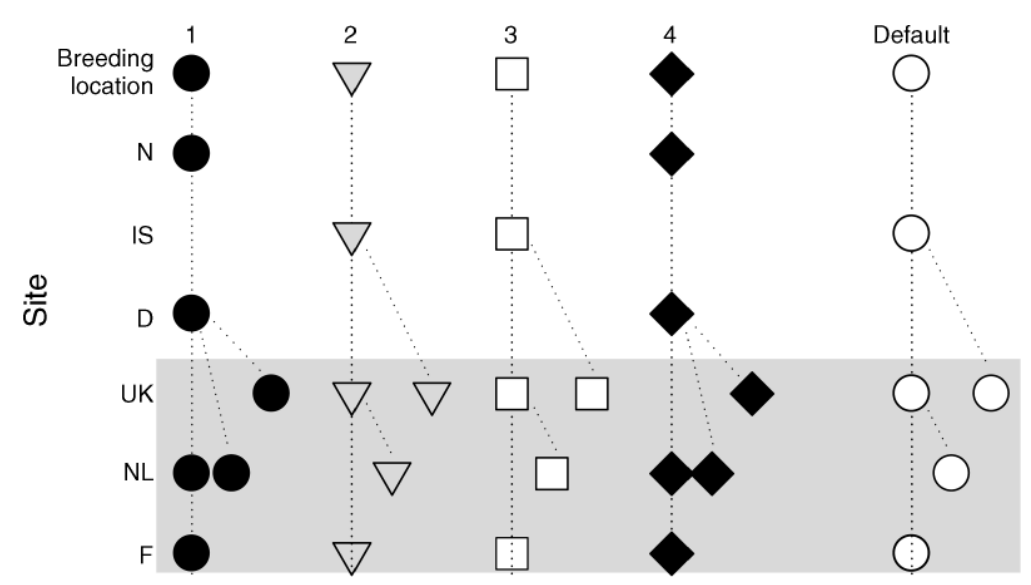

FIG. 3. Predicted migration routes for different breeding and wintering locations (see Fig. 1). The specific wintering location (shaded areas) was irrelevant in determining the migration route. Instead, the optimal route chosen was a function of breeding-site location. The doubled symbols for The Netherlands and the United Kingdom indicate scenarios in which those countries were used as wintering (i.e., starting) locations.

intake rates increased on sites along the default route, i.e., from France via United Kingdom and Iceland to the breeding grounds, birds adjusted only staging times, but did not alter the route. Under these conditions, birds made longer use of sites with higher-than-standard intake rates, and vice versa, stayed for shorter times when intake rates were lower than standard (Fig. 4). Thus, effects of altered intake rates were not only seen on the site where the change occurred, but had widerranging impacts also on other sites. At low intake rate levels in France, for instance, birds minimized the time spent at this site and instead stayed longer in the United Kingdom and Iceland.

However, the migration route was changed when either (a) intake rates on the default sites (France, United Kingdom, Iceland) were below standard settings, resulting in avoidance of these sites, or (b) when intake rates on nondefault sites (Netherlands, Germany, Norway) were higher than standard, and consequently, birds made use of their favorable conditions (Fig. 4c).

Varying energy expenditure showed a pattern diametrically opposed to that of varying intake rates; increasing the expenditure on a site resulted in the birds skipping this site and favoring low-expenditure sites (not shown).

Survival in these scenarios was high throughout (survival always $>85 \%$, mostly $>90 \%$ ), with the exception that energy budgets on the starting (wintering) site were negative, i.e., DEE higher than intake rates (not shown). Furthermore, there was no obvious pattern between survival and changed intake rates or DEE because of the aforementioned adjustments in migration routes and staging times.

\section{Predation risk}

Increasing predation risk typically resulted in the avoidance of risky sites, and vice versa, decreasing risk resulted in a preference for such safer sites (Fig. 5a-d).
However, there were clear differences in the degree to which site use was affected. Moreover, the effects depended greatly on which predation risk coefficient was changed.

Throughout the range tested, changes in background predation risk never led to a change in the route taken (always the standard route, France, United Kingdom, Iceland; Fig. 5a) but only to the adjustment of staging times. When, for instance, predation risk in France changed, birds were predicted to reduce staging time there, and instead, stayed (much) longer in the United Kingdom, while the use of Iceland was hardly affected. Interestingly, the change in use of staging sites occurred in a rather narrow range: When varying background predation between $1.2^{-5}$ and $2.0^{-5}$, birds switched from an extensive use of France to almost complete avoidance (Fig. 5b).

The response of the birds to changes in foragingintensity-dependent predation risk also depended on where the change took place. Higher than standard predation risk on sites of the default route (United Kingdom and Iceland) led to a skipping of these dangerous sites. Similarly, sites not on the default route (Netherlands, Germany, and Norway) were used when predation risk at these sites was lowered. The only exception to these general patterns was France, where a low predation risk resulted in an extremely long staging duration and a direct flight to Iceland, skipping the United Kingdom (Fig. 5a, c).

Changes in migration routes also resulted from increases in mass-dependent predation risk coefficient, but, with the exception of Norway, decreasing this coefficient hardly affected the migration route (Fig. 5a, d).

Survival under changing predation risk was also generally very high (always $>85 \%$, mostly $>90 \%$, not shown). Although survival declined with increasing background predation risk, this relation disappeared when the background predation risk became higher than 

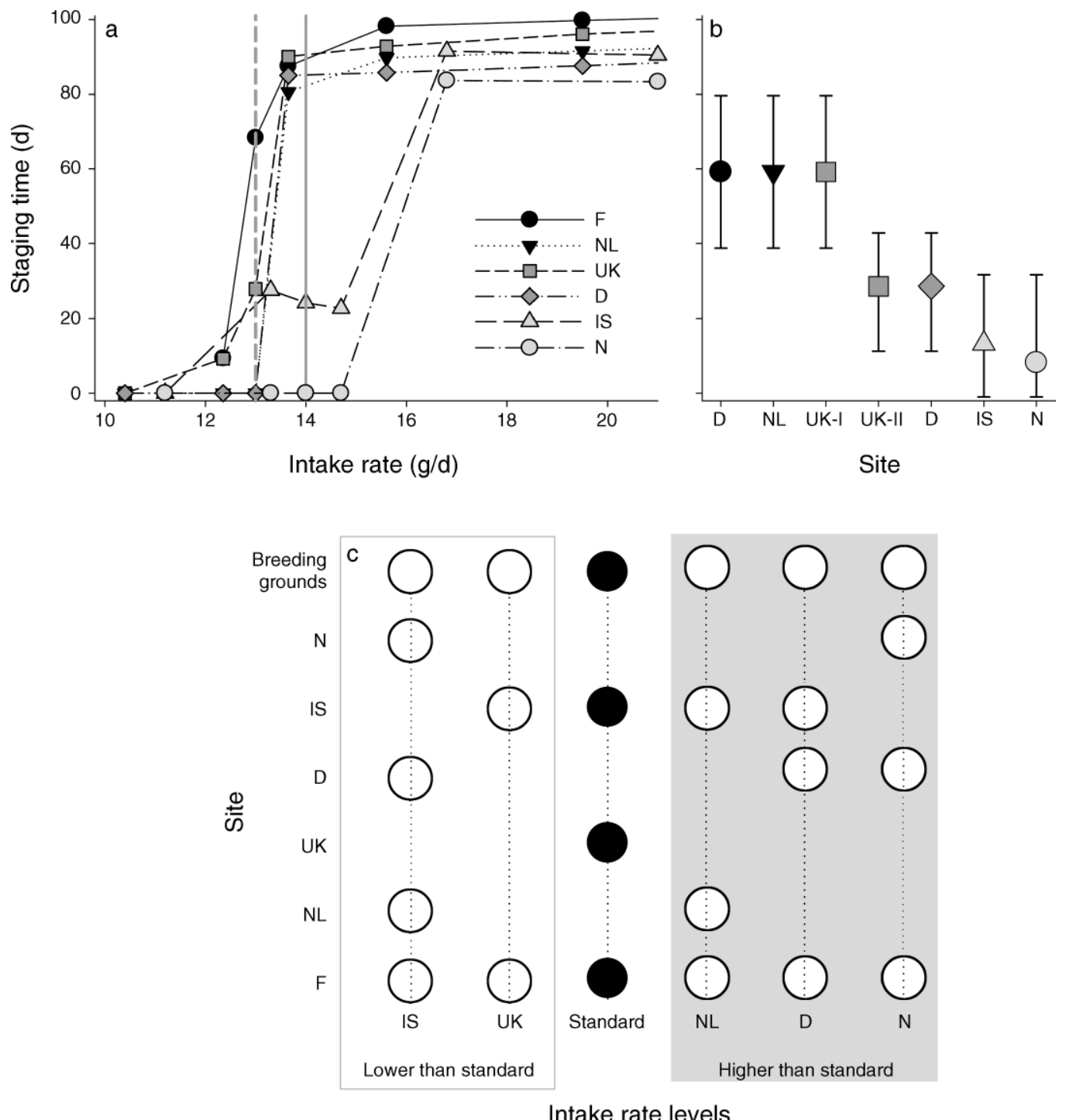

FIG. 4. (a) The relation between intake rate (in equivalents of grams of fuel per day) and predicted staging time for the six wintering and staging sites considered in the model; indicated are the default values for intake rates in France (F), The Netherlands (NL), the United Kingdom (UK), Germany (D), Iceland (IS), and Norway (N). (b) For comparison the empirical staging times from Fig. 1 are also shown, indicating the average staging times (symbols), and how they may increase or decrease by considering arrival and departure periods (error bars). If intake rates on a particular site were below the standard value, staging time on this site was severely reduced. Birds preferred sites with even slightly higher-than-standard intake rates. Accordingly, panel (c) shows predicted migration routes between the wintering sites in France and the (average) breeding site when intake rates on wintering and stopover sites were changed. Besides changing staging times, new migration routes appeared when intake rates on particular sites were changed, e.g., when intake rates in Iceland or the United Kingdom were lower or when intake rates in The Netherlands, Germany, or Norway were higher compared to the standard parameter setting.

in the standard parameter setting. Similarly, no clear pattern appeared for the relation between survival and the other two facets of predation risk, as birds were able to respond to these changes by reducing staging time or avoiding risky sites altogether.

\section{DiscusSiOn}

Our modeling exercise has shown that all three of our tested hypotheses might lead to variations in migration routes of Icelandic Knots. Among the tested hypotheses, the breeding location hypothesis is the simplest and also the only hypothesis for which independent empirical evidence exists. Birds breeding in Canada and West Greenland were predicted to migrate via Iceland, whereas birds breeding in East Greenland were predicted to migrate via Norway. Recent studies in Norway support this prediction (at least indirectly), as Knots departing to their breeding grounds from Norway do so at significantly lower mass than birds departing from Iceland, suggesting that the Norway birds do not 

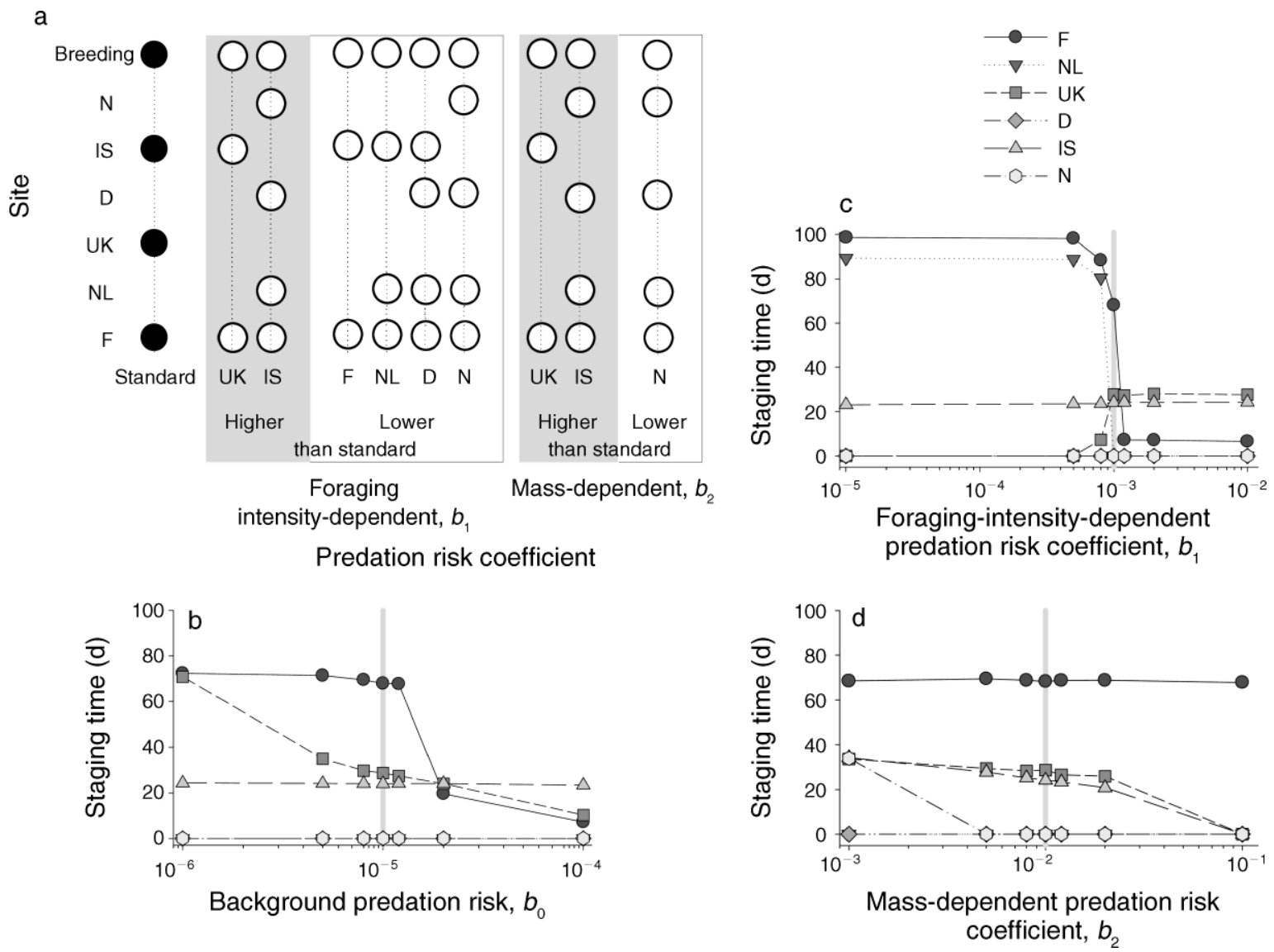

FIG. 5. Changes in predation risk led to (a) different predicted migration routes and (b-d) different staging times. Only variations in foraging-intensity-dependent and mass-dependent predation risk coefficients affected the choice of migration route. Alterations in background predation risk led only to adjustments in staging time. Panels (b)-(d) show predicted staging times under changes in (b) background predation risk, (c) foraging-intensity-dependent predation risk, and (d) mass-dependent predation risk. The default values for all three parameters are indicated by the gray, vertical reference lines. For comparison to empirical staging times, see Figs. 2 and 4b.

penetrate as far west into the Canadian breeding areas as those staging in Iceland (Wilson et al. 2007). In addition, in the model the wintering location was irrelevant for the choice of route, which is supported by the limited empirical data available (Davidson and Wilson 1992). The only published evidence of direct observations on individual birds comes from two birds marked on the breeding grounds in Alert (between sites 3 and 4, Fig. 1) and in Zackenberg (Danish research station; in the vicinity of site 4) and seen in Porsanger, Norway (Wilson et al. 2006). Confirmation of our findings waits for more individual itineraries to be confirmed.

Implicitly, the breeding location hypothesis assumes that individual birds head for specific locations in the Arctic, regardless of how this is motivated, either because they return to their birthplaces (natal philopatry) or to sites where they have successfully bred in previous years (site tenacity). Unfortunately, not much is known about the degree of philopatry or site tenacity in knots (but see Spaans et al. 2009), nor about the fidelity to stopover sites in migratory birds in general. It is generally thought that geese, swans, and waders are more faithful than passerines (Catry et al. 2004), simply due to their higher habitat selectivity, lower sensitivity to weather during flight (wind drift), and the fact that routes are often socially transmitted (migration in flocks, younger birds learn "best" routes from older, more experienced individuals).

In addition to different breeding site destinations, quality of the sites in terms of fueling possibilities and safety can also have an important influence on the staging times on sites, and thus, ultimately, on the route taken (Alerstam and Lindström 1990). A general pattern for all parameters tested is that changing a parameter on a particular site not only had consequences for the staging behavior on the site where the change happened, but also on the staging behavior at preceding and subsequent sites, a phenomenon generally predicted for migratory animals and referred to as interdependence of site use (e.g., Klaassen et al. 2006, Bauer et al. 2008). 
The model predicted that energy budgets resulting from the interplay between intake rates and energy expenditure can strongly determine the choice of migration routes. As soon as a site offered a slightly higher food supply (or lower energy expenditure), birds in the model favored such sites over other less productive or more costly sites. In reality, many factors contribute to the determination of intake rates: availability and abundance of prey species, digestive constraints imposed by gizzard size (van Gils et al. 2005), and intraspecific competition (e.g., Goss-Custard et al. 2001). Within a population, young individuals are often the prime victims of competition, because dominant individuals expel them from high-quality areas such that they suffer lower intake rates than the experienced adults. Although we have not explicitly incorporated density dependence or intrapopulation differences (e.g., between sexes or age groups) in fueling rates, lowering the maximum intake rates in the model imitates such situations, which part of the population might experience. Thus if, for instance, young individuals have lower fueling rates than adults, they would also be predicted to differ from adults in their staging times and migration routes (See Reasons for existence of multiple routes).

Similarly, energy expenditure mainly depends on local climatic conditions. Climate change predicts average temperature changes of $\sim 1.4^{\circ} \mathrm{C}$ (range $0.5^{\circ}-2.8^{\circ} \mathrm{C}$ [IPCC 2007, Van Vuuren et al. 2008]) over the next 100 years, but these will neither affect all sites equally nor simultaneously. Such temperature changes will have direct consequences for knots as they impact on energy expenditure, and also influence the birds indirectly via availability of their prey species. Our model predicted that Icelandic Knots would choose a different migration route when energy expenditure or food availability changed on sites. Thus, the effect of temperature alone on energy expenditure and temperature differences between sites may lead to changes in migration routes, as a consequence of climate change. Furthermore, as prey species will also react to temperature changes, but possibly in a different manner, food availability likely changes as well. The different reactions to changing temperature regimes of both the knots and their prey may potentially result in a trophic mismatch, with considerable demographic consequences (e.g., Visser 2008).

Changes in predation risk could also strongly determine migration routes. As a general pattern, birds tended to avoid risky sites, a behavior that has already been shown in many other species (e.g., in Western Sandpipers, Calidris mauri [Ydenberg et al. 2004]). Thus, this finding by itself is not surprising, but as an extension to existing knowledge, we showed that the three facets of predation risk contributed differently. Increased background predation risk let birds adjust staging times, but did not change the migration route. This observation is similar to the reaction of Western Sandpipers, which shortened their length of stay over a period when the population of their major predator (Peregrine Falcons,
Falco peregrinus) had recovered (Ydenberg et al. 2004). In contrast, changes in foraging-intensity or massdependent predation risk more often led to an adjustment of the route (Ydenberg et al. 2002) than to changes in staging times alone. Knots can adjust their behavior to deal with higher risks, e.g., by being more vigilant or choosing safer foraging sites (Hilton et al. 1999), and by trading off food supply against danger (e.g., Pomeroy et al. 2006).

Unfortunately, despite its apparent importance as a driving force of migratory behavior, little information exists on predation risk along the flyways of Icelandic Knots. However, this may rapidly change, since the role of predation in migratory systems is increasingly being addressed, including its effects on staging knots (van den Hout et al. 2007).

Our model makes strong assumptions about the information available to the migrants. It is assumed that individuals are omniscient, and their migratory decisions are the optimal response to environmental conditions along the entire route. Although this seems a rather extreme assumption, there is probably a high selection for individuals choosing optimal routes that shape their migration behavior, while suboptimal behavior results in higher mortality rates. In addition to innate behaviors, individuals may also learn and integrate site conditions along their migratory route during their first migration(s), during which they do not aim for breeding but rather explore environments for future benefits.

\section{Reasons for existence of multiple routes}

Since a specific parameter set (i.e., a set of site-specific functions for food availability, energy expenditure, and predation risk) will typically result in a single optimal route, it seems paradoxical that we use our model to investigate reasons for the existence of multiple routes. However, individual differences in the perception of the environment might exist within the population, resulting in different behaviors being adaptive. Such differences might also relate to the specific (feeding) skills of individuals. Thus, should we be able to identify subgroups in a population that experience, e.g., different intake rates or predation pressures, we predict optimal behaviors to be different for these groups, resulting in multiple routes to their destinations. This phenomenon is referred to as differential migration (e.g., Nebel et al. 2004). Indeed, such differential migration has been observed in many species in relation to age, sex, and size. Young birds are often more predation prone due to inexperience or because they are forced out of safe foraging spots by adult birds (e.g., Nebel 2007, van den Hout et al. 2007). Female Western Sandpipers migrate farther south than males, to less profitable but safer sites (Lank et al. 2003, Nebel and Ydenberg 2005), and lean Western Sandpipers choose riskier sites than their heavy conspecifics (Ydenberg et al. 2002). 
Although most evidence so far comes from birds, because this is probably the best-studied migrant group (Bauer et al. 2009), differences in migration routes between sexes, or groups separated by age or size, can similarly be found in many other species and taxa. For example, larger individuals of cod migrate farther south (Jørgensen et al. 2008), and there are different strategies of age-dependent migration in herring (Corten 2001), and sex-specific migrations in elephant seals (Le Boeuf et al. 2000).

Our findings provide several potential explanations for the fact that Icelandic Knots use a diverse array of migration routes. However, although based on a wealth of already available data, the ultimate verification of our predictions still lies ahead, requiring specific additional empirical data. Given the technological advances in the field, this need not, however, be a long shot. Satellite tracking tags yielding individual itineraries that could be compared to our predictions have not been reduced to the size required for knots, but hopeful developments exist. Examples are the spectacular satellite tracking of Bar-tailed Godwits (Limosa lapponica) that cross the Pacific on their migrations between Alaska and New Zealand (Battley 2006, Gill et al. 2009), and the development of dedicated small-animal tracking systems from space (Wikelski et al. 2007). Indirect tracking methods might be also be employed to unravel the routes travelled, e.g., analyses of stable isotopes for the identification of the different locations visited during the annual or life cycle. Examples can be found for birds (Atkinson et al. 2005), insects (Brattstrom et al. 2008), turtles (Hatase et al. 2006), and sea mammals (Witteveen et al. 2009). It is a huge effort to measure parameters at all potential sites, and prioritization is required. To identify crucial parameters and direct these sampling efforts, the modeling approach presented here might prove a useful tool, not only for the case of the migratory system of the Icelandic Knot, but also for other taxa. The approach can be extended to many species of birds, but equally well to other long-distance migrants at sea or on the land.

\section{ACKNOWLEDGMENTS}

We highly appreciated discussions with Ingrid Tulp and Hans Schekkerman and helpful comments from Theunis Piersma, Jim Wilson, Gudmundur A. Gudmundsson, and an anonymous reviewer. S. Bauer was funded by NWO project 816.01.007. This is publication 4619 of the Netherlands Institute of Ecology (NIOO-KNAW).

\section{Literature Cited}

Alerstam, T., A. Hedenström, and S. Åkesson. 2003. Longdistance migration: evolution and determinants. Oikos 103 : $247-260$.

Alerstam, T., and $\AA$. Lindström. 1990. Optimal bird migration: the relative importance of time, energy, and safety. Pages 331-351 in E. Gwinner, editor. Bird migration. Springer, Berlin, Germany.

Atkinson, P. W., A. J. Baker, R. M. Bevan, N. A. Clark, K. B. Cole, P. M. Gonzalez, J. Newton, L. J. Niles, and R. A. Robinson. 2005. Unravelling the migration and moult strategies of a long-distance migrant using stable isotopes: Red Knot Calidris canutus movements in the Americas. Ibis 147:738-749.

Battley, P. F. 2006. Consistent annual schedules in a migratory shorebird. Biology Letters 2:517-520.

Bauer, S., Z. Barta, B. J. Ens, G. C. Hays, J. M. McNamara, and M. Klaassen. 2009. Animal migration: linking models and data beyond taxonomic limits. Biology Letters 5(4):433435.

Bauer, S., M. van Dinther, K. A. Høgda, M. Klaassen, and J. Madsen. 2008. The consequences of climate-driven stop-over sites changes on migration schedules and fitness of Arctic geese. Journal of Animal Ecology 77:654-660.

Best, P. B., K. P. Findlay, K. Sekiguchi, V. M. Peddemors, B. Rakotonirina, A. Rossouw, and D. Gove. 1998. Winter distribution and possible migration routes of humpback whales Megaptera novaeangliae in the southwest Indian Ocean. Marine Ecology Progress Series 162:287-299.

BirdLife International. 2004. Birds in the European Union: a status assessment. BirdLife International, Wageningen, The Netherlands.

Boyd, H., and T. Piersma. 2001. Changing balance between survival and recruitment explains population trends in Red Knots Calidris canutus islandica wintering in Britain, 19691995. Ardea 89:301-317.

Brattstrom, O., L. I. Wassenaar, K. A. Hobson, and S. Akesson. 2008. Placing butterflies on the map-testing regional geographical resolution of three stable isotopes in Sweden using the monophagus peacock Inachis io. Ecography 31:490-498.

Brower, L. P. 1995. Understanding and misunderstanding the migration of the monarch butterfly (Nymphalidae) in North America: 1857-1995. Journal of the Lepidopterists Society 49:304-385.

Catry, P., V. Encarnacao, A. Araujo, P. Fearon, A. Fearon, M. Armelin, and P. Delaloye. 2004. Are long-distance migrant passerines faithful to their stopover sites? Journal of Avian Biology 35:170-181.

Corten, A. 2001. The role of "conservatism" in herring migrations. Reviews in Fish Biology and Fisheries 11:339361 .

Davidson, N. C., K. B. Strann, N. J. Crockford, P. R. Evans, J. Richardson, L. J. Standen, D. J. Townshend, J. D. Uttley, J. R. Wilson, and A. G. Wood. 1986. The origins of knots Calidris canutus in Arctic Norway in spring. Ornis Scandinavica $17: 175-179$.

Davidson, N. C., and J. R. Wilson. 1992. The migration system of European-wintering knots Calidris canutus islandica. Wader Study Group Bulletin 64(Supplement):39-51.

Drent, R., C. Both, M. Green, J. Madsen, and T. Piersma. 2003. Pay-offs and penalties of competing migratory schedules. Oikos 103:274-292.

Gill, R. E., T. L. Tibbitts, D. C. Douglas, C. M. Handel, D. M. Mulcahy, J. C. Gottschalck, N. Warnock, B. J. McCaffery, P. F. Battley, and T. Piersma. 2009. Extreme endurance flights by landbirds crossing the Pacific Ocean: ecological corridor rather than barrier? Proceedings of the Royal Society B 276:447-457.

Goss-Custard, J. D., A. D. West, R. A. Stillman, S. E. A. L. Durell, R. W. G. Caldow, S. McGrorty, and R. Nagarajan. 2001. Density-dependent starvation in a vertebrate without significant depletion. Journal of Animal Ecology 70:955-965.

Hatase, H., K. Sato, M. Yamaguchi, K. Takahashi, and K. Tsukamoto. 2006. Individual variation in feeding habitat use by adult female green sea turtles (Chelonia mydas): Are they obligately neritic herbivores? Oecologia 149:52-64.

Hays, G. C., V. J. Hobson, J. D. Metcalfe, D. Righton, and D. W. Sims. 2006. Flexible foraging movements of leatherback turtles across the north Atlantic Ocean. Ecology 87: $2647-2656$. 
Hilton, G. M., G. D. Ruxton, and W. Cresswell. 1999. Choice of foraging area with respect to predation risk in redshanks: the effects of weather and predator activity. Oikos 87:295-302.

Houston, A. I., and J. M. McNamara. 1999. Models of adaptive behaviour: an approach based on state. Cambridge University Press, Cambridge, UK.

IPCC. 2007. Climate Change 2007: synthesis report. Contribution of Working Groups I, II, and III to the Fourth Assessment. Report of the Intergovernmental Panel on Climate Change, Geneva, Switzerland.

Jørgensen, C., E. S. Dunlop, A. F. Opdal, and O. Fiksen. 2008. The evolution of spawning migrations: state dependence and fishing-induced changes. Ecology 89:3436-3448.

Klaassen, M., S. Bauer, J. Madsen, and T. Ingunn. 2006. Modelling behavioural and fitness consequences of disturbance for geese along their spring flyway. Journal of Applied Ecology 43:92-100.

Lank, D. B., R. W. Butler, J. Ireland, and R. C. Ydenberg. 2003. Effects of predation danger on migration strategies of sandpipers. Oikos 103:303-319.

Le Boeuf, B. J., D. E. Crocker, D. P. Costa, S. B. Blackwell, P. M. Webb, and D. S. Houser. 2000. Foraging ecology of northern elephant seals. Ecological Monographs 70:353-382.

Morrison, R. I. G., N. C. Davidson, and J. R. Wilson. 2007. Survival of the fattest: body stores on migration and survival in red knots Calidris canutus islandica. Journal of Avian Biology 38:479-487.

Nebel, S. 2007. Differential migration of shorebirds in the East Asian-Australasian flyway. Emu 107:14-18.

Nebel, S., A. Cloutier, and G. J. Thompson. 2004. Molecular sexing of prey remains permits a test of sex-biased predation in a wintering population of western sandpipers. Proceedings of the Royal Society B 271:S321-S323.

Nebel, S., and R. Ydenberg. 2005. Differential predator escape performance contributes to a latitudinal sex ratio cline in a migratory shorebird. Behavioral Ecology and Sociobiology 59:44-50.

Newton, I. 2007. Weather-related mass-mortality events in migrants. Ibis 149:453-467.

Piersma, T. 2007. Using the power of comparison to explain habitat use and migration strategies of shorebirds worldwide. Journal of Ornithology 148:S45-S59.

Piersma, T., et al. 2005. Fuel storage rates before northward flights in Red Knots worldwide. Pages 262-273 in R. Greenberg and P. P. Marra, editors. Birds of two worlds: the ecology and evolution of migration. Johns Hopkins University Press, Baltimore, Maryland, USA.

Pomeroy, A. C., R. W. Butler, and R. C. Ydenberg. 2006. Experimental evidence that migrants adjust usage at a stopover site to trade off food and danger. Behavioral Ecology 17:1041-1045.

Spaans, B., M. Brugge, A. Dekinga, H. Horn, L. van Kooten, and T. Piersma. 2009. Oost west, thuis best? Op welke schaal benutten individuele Kanoeten het Nederlandse Waddengebied. Limosa, in press.

van den Hout, P. J., B. Spaans, and T. Piersma. 2007. Differential mortality of wintering shorebirds on the Banc
d'Arguin, Mauritania, due to predation by large falcons. Ibis 150:219-230.

van Gils, J. A., P. F. Battley, T. Piersma, and R. Drent. 2005. Reinterpretation of gizzard sizes of red knots world-wide emphasises overriding importance of prey quality at migratory stopover sites. Proceedings of the Royal Society B 272: 2609-2618.

Van Vuuren, D. P., et al. 2008. Temperature increase of 21st century mitigation scenarios. Proceedings of the National Academy of Sciences (USA) 105:15258-15262.

Visser, M. E. 2008. Keeping up with a warming world; assessing the rate of adaptation to climate change. Proceedings of the Royal Society B 275:649-659.

Weber, T. P., B. J. Ens, and A. I. Houston. 1998. Optimal avian migration: a dynamic model of fuel stores and site use. Evolutionary Ecology 12:377-401.

Weber, T. P., A. I. Houston, and B. J. Ens. 1999. Consequences of habitat loss at migratory stopover sites: a theoretical investigation. Journal of Avian Biology 30:416-426.

Wiersma, P., and T. Piersma. 1994. Effects of microhabitat, flocking, climate and migratory goal on energy-expenditure in the annual cycle of Red Knots. Condor 96:257-279.

Wikelski, M., R. W. Kays, N. J. Kasdin, K. Thorup, J. A. Smith, and G. W. Swenson. 2007. Going wild: what a global small-animal tracking system could do for experimental biologists. Journal of Experimental Biology 210:181-186.

Wilcove, D. S., and M. Wikelski. 2008. Going, going, gone: Is animal migration disappearing? PLoS Biology 6:1361-1364.

Wilson, J., W. J. A. Dick, V. Frivoll, M. Harrison, T. Johnsen, K. M. Soot, D. Stanyard, K.-B. Strann, R. Strugnell, B. Swinfen, R. Swinfen, and R. Wilson. 2007. The migration of Red Knots through Porsangerfjord in spring 2007: a progress report on the Norwegian Knot Project. Wader Study Group Bulletin 114:51-55.

Wilson, J., and K.-B. Strann. 2005. The migration of Red Knots through Porsangerfjord in spring 2005: a progress report on the Norwegian Knot Project. Wader Study Group Bulletin 108:66-69.

Wilson, J., R. Swinfen, B. Swinfen, K.-B. Strann, T. Johnsen, V. Frivoll, R. Wilson, D. Stanyard, M. Harrison, and R. Strugnell. 2006. The migration of Red Knots through Porsangerfjord in spring 2006: a progress report on the Norwegian Knot Project. Wader Study Group Bulletin 111: $54-58$.

Witteveen, B. H., G. A. J. Worthy, K. M. Wynne, and J. D. Roth. 2009. Population structure of North Pacific humpback whales on their feeding grounds revealed by stable carbon and nitrogen isotope ratios. Marine Ecology Progress Series 379:299-310.

Ydenberg, R. C., R. W. Butler, D. B. Lank, C. G. Guglielmo, M. Lemon, and N. Wolf. 2002. Trade-offs, condition dependence and stopover site selection by migrating sandpipers. Journal of Avian Biology 33:47-55.

Ydenberg, R. C., R. W. Butler, D. B. Lank, B. D. Smith, and J. Ireland. 2004. Western sandpipers have altered migration tactics as peregrine falcon populations have recovered. Proceedings of the Royal Society B 271:1263-1269.

\section{APPENDIX A}

Optimal-migration model description (Ecological Archives E091-121-A1).

\section{APPENDIX B}

Site-specific energy budgets: intake rates and energy expenditure (Ecological Archives E091-121-A2). 